\title{
Peroxisome Proliferator-Activated Receptors: From Genes to Physiology
}

\author{
Steven A. Kliewer, H. ERIC Xu, \\ Millard H. Lambert, and Timothy M. Willson \\ Glaxo Wellcome, Inc., 5 Moore Drive, Research Triangle Park, North Carolina 27709
}

\begin{abstract}
The peroxisome proliferator-activated receptors (PPAR $\alpha, \gamma, \delta)$ are members of the nuclear receptor superfamily of ligand-activated transcription factors that have central roles in the storage and catabolism of fatty acids. Although the three PPAR subtypes are closely related and bind to similar DNA response elements as heterodimers with the 9-cis retinoic acid receptor RXR, each subserves a distinct physiology. PPAR $\alpha$ (NR1C1) is the receptor for the fibrate drugs, which are widely used to lower triglycerides and raise high-density lipoprotein cholesterol levels in the treatment and prevention of coronary artery disease. In rodents, PPAR $\alpha$ agonists induce hepatomegaly and stimulate a dramatic proliferation of peroxisomes as part of a coordinated physiological response to lipid overload. PPAR $\gamma$ (NR1C3) plays a critical role in adipocyte differentiation and serves as the receptor for the glitazone class of insulin-sensitizing drugs used in the treatment of type 2 diabetes. In contrast to PPAR $\alpha$ and PPARy, relatively little is known about the biology of PPAR $\delta$ (NR1C2), although recent findings suggest that this subtype also has a role in lipid homeostasis. All three PPARs are activated by naturally occurring fatty acids and fatty acid metabolites, indicating that they function as the body's fatty acid sensors. Three-dimensional crystal structures reveal that the ligand-binding pockets of the PPARs are much larger and more accessible than those of other nuclear receptors, providing a molecular basis for the promiscuous ligand-binding properties of these receptors. Given the fundamental roles that the PPARs play in energy balance, drugs that modulate PPAR activity are likely to be useful for treating a wide range of metabolic disorders, including atherosclerosis, dyslipidemia, obesity, and type 2 diabetes.
\end{abstract}

\section{Introduction}

Peroxisomes are organelles that are involved in the $\beta$ oxidation of long-chain chain fatty acids and the catabolism of cholesterol to bile acids (Vamecq and Draye, 1989). In rodents, the number and size of peroxisomes are dramatically increased in the liver and, to a lesser extent, the heart and kidney in response to treatment with a variety of different amphipathic acids, including hypolipidemic drugs and plasticizers, which are collectively referred to as "peroxisome proliferators." Peroxisome proliferation in rodents is accompanied by a marked hepatomegaly and increases in the transcription of genes involved in peroxisomal and 
microsomal oxidation of fatty acids as well as by alterations in lipid metabolism, including reductions in serum triglyceride and cholesterol levels. Under normal physiological conditions, peroxisomal $\beta$ oxidation represents only a minor pathway for fatty acid catabolism relative to the mitochondrial system. However, the peroxisomal pathway is engaged in rodents during periods of lipid overload (e.g., precipitated by high-fat diets or metabolic disturbances). Interestingly, the phenomenon of peroxisome proliferation does not occur in humans, although peroxisomes are essential organelles (Vamecq and Draye, 1989). The molecular basis for this difference between species is not yet clear.

In 1990, Issemann and Green reported the cloning and initial characterization of a novel murine orphan nuclear receptor that was activated by a range of established peroxisome proliferators (Issemann and Green, 1990). This new receptor originally was named the peroxisome proliferator-activated receptor (PPAR) but it is now referred to as PPAR $\alpha$. Like other members of the nuclear receptor superfamily, PPAR $\alpha$ contains an approximately 70 amino acid DNAbinding domain comprised of two highly conserved zinc fingers and a C-terminal ligand-binding domain (LBD) of approximately 250 amino acids. In addition to its ligand-binding capabilities, the LBD contains dimerization and transcriptional activation domains, including the well-characterized transcriptional activation function 2 (AF-2), which is embedded in the extreme C-terminal portion of the receptor. The $\mathrm{N}$-terminal domain of PPAR $\alpha$ is less well characterized but appears to encode an additional transcriptional activation function.

In 1992, the Wahli laboratory reported the cloning of the Xenopus laevis ortholog of PPAR $\alpha$ (Dreyer et al., 1992). Like the mouse receptor, the Xenopus PPAR $\alpha$ was activated by micromolar concentrations of peroxisome proliferators. The Wahli group also reported the cloning of two closely related orphan receptors encoded by distinct genes, which they named PPAR $\beta$ and PPAR $\gamma$. Several groups subsequently reported the cloning of mammalian orthologs of PPAR $\beta$ and PPAR $\gamma$. Although PPAR $\alpha$ and PPAR $\gamma$ are quite highly conserved across species, the third mammalian PPAR subtype diverged considerably from Xenopus to mammals, leaving in question whether these orphan receptors were, in fact, orthologs or paralogs (Figure 1A). The murine clone was named PPAR $\delta$ because of this divergence (Kliewer et al., 1994). However, the recent cloning and characterization of the chicken PPAR $\beta$ has made it possible to construct an evolutionary tree from which it is apparent that the Xenopus PPAR $\beta$ and the mammalian PPAR $\delta$ are, in fact, divergent orthologs (Takada et al., 2000). We will refer to this subtype as PPAR $\delta$ in the rest of this chapter. The PPAR nomenclature for PPAR $\delta$ and PPAR $\gamma$ is a misnomer, since neither of these PPAR subtypes has been associated with peroxisome proliferation. 
A

$\operatorname{PPAR} \alpha$

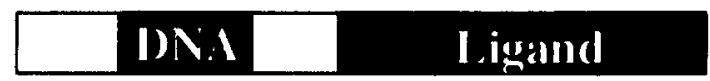

PPAR $\gamma$

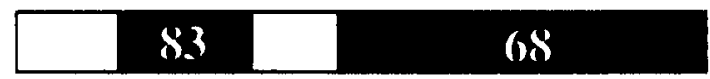

PPAR $\delta$

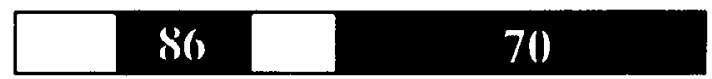

B

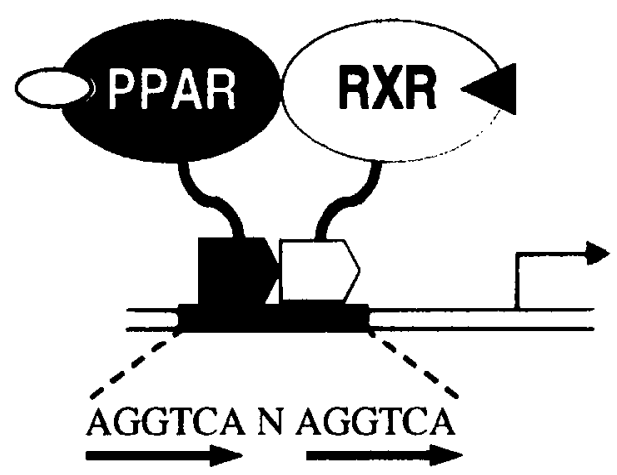

FIG. 1. The PPAR family and its DNA-binding properties. (A) The murine PPAR subfamily. The DNA and ligand-binding domains are indicated. Numbers represent percent amino acid identity. (B) The PPARs bind to DR-1-type DNA response elements as heterodimers with RXR. The PPAR/RXR heterodimer can be activated by ligands for either PPAR or RXR.

Each of the three PPAR subtypes is expressed in a distinct, tissue-specific pattern. PPAR $\alpha$ is highly expressed in liver, heart, kidney, skeletal muscle, and brown adipose, tissues that are metabolically very active. PPAR $\gamma$ is most-highly expressed in white and brown adipose tissue, large intestine, and spleen. In contrast to PPAR $\alpha$ and PPAR $\gamma$, which are abundantly expressed in just a few tissues, PPAR $\delta$ is expressed in virtually all tissues at comparable levels. Like several other members of the nuclear receptor superfamily, the PPARs bind to DNA as obligate heterodimers with the 9-cis retinoic acid receptors (RXRs) (Figure 1B). The PPAR/RXR heterodimers bind to two half sites of the consensus 
sequence AGGTCA, organized as a direct repeat with a single nucleotide spacer, a so-called DR-1 motif. Peroxisome proliferator response elements (PPREs) have been identified in the transcriptional regulatory regions of numerous genes involved in carbohydrate and lipid metabolism. There is emerging evidence that optimal binding sites differ slightly for each PPAR subtype. These subtle differences in binding site preference, together with the differences in tissue expression patterns, undoubtedly contribute to the different biologies of the three PPAR subtypes.

Shortly after their cloning, it was noted that the PPARs are unusual in their ligand activation properties in two important respects. First, they are relatively promiscuous, compared to most other nuclear receptors (e.g., the steroid hormone and retinoid receptors). The PPARs are activated by structurally diverse amphipathic acids, including both natural and synthetic compounds. Interestingly, this promiscuity has since been observed with several other orphan nuclear receptors, including the pregnane $\mathrm{X}$ receptor $(\mathrm{PXR})$ and the constitutive androstane receptor (CAR) (Moore et al., 2000). Second, the PPAR/RXR heterodimers are "permissive" for activation by 9-cis retinoic acid and synthetic RXR ligands through the RXR subunit of the heterodimer (Kliewer et al., 1992). Although the PPAR $\alpha / R X R$ complex was the first permissive heterodimer to be characterized, we now know that heterodimers formed between RXR and several other nuclear receptors - including all three PPAR subtypes, the liver $\mathrm{X}$ oxysterol receptors (LXRs), and the farnesoid X bile acid receptor (FXR) - are permissive for activation by RXR ligands (Mangelsdorf and Evans, 1995).

During the past 7 years, our nuclear receptor group at Glaxo Wellcome has focused much of its effort on the identification of PPAR subtype-selective agonists and antagonists and the use of these chemical tools to uncover the physiological roles of the PPARs and the therapeutic utility of PPAR ligands. We refer to this approach of using small-molecule ligands to unravel the biology of orphan nuclear receptors as "reverse endocrinology" (Kliewer et al., 1999; Willson et al., 2000a). In order to understand how ligands modulate PPAR activity at the molecular level, we have determined the three-dimensional structures of PPARs in the presence of agonists, partial agonists, and antagonists by $x$-ray crystallography. This review will focus on the insights into the structure and function of the PPARs provided by reverse endocrinology.

\section{PPAR $\alpha$ : The Fibrate Receptor}

The discovery that PPAR $\alpha$ is activated by a range of peroxisome proliferators, together with its high expression in tissues in which peroxisome proliferation occurs, first suggested that PPAR $\alpha$ might mediate this biological phenomenon (Isseman and Green, 1990). This hypothesis was confirmed in dramatic fashion 
by the generation of mice lacking functional PPAR $\alpha$ (Lee et al., 1995). PPAR $\alpha-$ null mice were viable and normal in appearance but did not display any evidence of characteristic morphological or biochemical changes when treated with efficacious peroxisome proliferators such as clofibrate and Wy14,643. Subsequent studies revealed that PPAR $\alpha$-null mice have increased basal plasma levels of cholesterol and become obese with age (Peters et al., 1997; Costet et al., 1998). These data provided strong evidence that PPAR $\alpha$ mediates the hypolipidemic effects of fibrates and other peroxisome proliferators.

The hypolipidemic fibrates - including gemfibrozil, fenofibrate, and bezafibrate - are a class of drugs widely prescribed in western countries for reducing triglyceride levels, a risk factor for cardiovascular disease. Fibrates have the added benefit of raising levels of high-density lipoprotein (HDL), or "good," cholesterol and reducing levels of low-density lipoprotein (LDL), or "bad," cholesterol in certain subpopulations of dyslipidemic individuals. The fibrates originally were developed as cardiovascular drugs through optimization of their in vivo activity in rodent models of hyperlipidemia prior to the discovery of the PPARs. Although these drugs activate PPAR $\alpha$ in vitro, they do so only at concentrations in the high micromolar range, which may explain why large doses (i.e., 200-1200 mg/day) are required for clinical activity. Moreover, the fibrates in clinical use are only weakly selective for PPAR $\alpha$ over the other two PPAR subtypes (Brown et al., 1999).

A search for more-potent fibrates by scientists at Burroughs Wellcome led to synthesis of a series of urea-substituted (ureido) fibrate analogs that were active at greater than 100-fold lower doses in rodent models of hyperlipidemia (Hawke et al., 1997). In our hands, these same compounds were very potent in cell-based PPAR $\alpha$ activation assays, activating the receptor with half-maximal effective concentrations in the low nanomolar range (Kliewer et al., 1997; Brown et al., 1999). The strong correlation between the in vivo and in vitro potencies of these compounds provided additional evidence that PPAR $\alpha$ is the molecular target for the hypolipidemic effects of fibrates (Brown et al., 1999).

The lack of potency of the fibrates in clinical use had raised the question whether they exerted their effects on PPAR $\alpha$ activity by binding directly to the receptor or by an indirect mechanism. The discovery of potent PPAR $\alpha$ activators provided us with the reagents necessary to address this question. Standard binding assays performed with a tritiated derivative of the potent ureido fibrate GW 2331 (Figure 2) showed that this compound bound directly to recombinant PPAR $\alpha$ LBD with a $K_{d}$ of $\sim 10 \mathrm{nM}$ (Kliewer et al., 1997). In competition binding assays, a series of established hypolipidemic agents and peroxisome proliferators efficiently displaced $\left[{ }^{3} \mathrm{H}\right] \mathrm{GW} 2331$ from the PPAR $\alpha$ LBD. These data provide strong evidence that the fibrates and other hypolipidemic agents mediate their therapeutic 


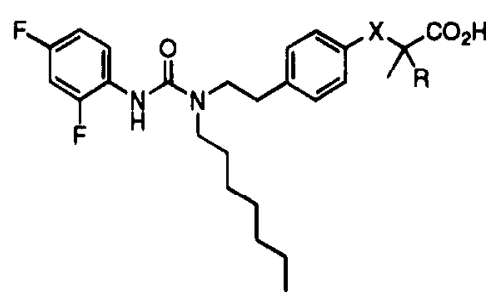

GW 2331, $X=0, R=E t$

GW 9578, $X=S, R=M e$<smiles>CN(CCOc1ccc(CC2SC(=O)NC2=O)cc1)c1ccccn1</smiles>

rosiglitazone

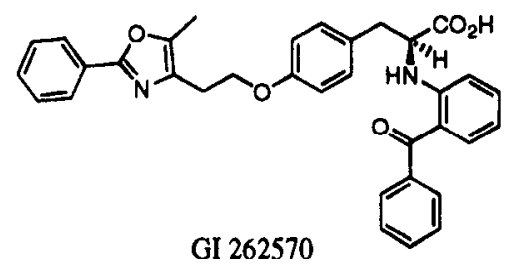

GI 262570<smiles>CCCCCCCC[C@H]1S[C@@H](CC(=O)N(Cc2ccccc2)Cc2ccccc2)C(=O)N1CCCCc1ccc(C(=O)O)cc1</smiles>

GW 0072

GW 2433

FIG. 2. Chemical structures of synthetic PPAR ligands.

effects by direct binding to PPAR $\alpha$. Ligand-sensing assays that detect ligand-induced conformational changes in PPAR $\alpha$ also have been used to show that fibrates and other peroxisome proliferators bind directly to this nuclear receptor (Dowell et al., 1997; Forman et al., 1997; Krey et al., 1997).

The availability of potent, selective PPAR $\alpha$ ligands as chemical tools has provided new, unexpected insights into the biology of this receptor. In addition to dramatically reducing serum triglyceride levels, the potent rodent PPAR $\alpha$-selective ureido fibrate GW 9578 (Figure 2) recently was shown to prevent hyperinsulinemia in rodent models of insulin resistance (Guerre-Millo et al., 2000). Since hyperlipidemia and insulin resistance are independent risk factors for coronary heart disease in diabetes patients, the development of potent human PPAR $\alpha$ - 
selective agonists may lead to more-effective drugs for the prevention of cardiovascular mortality.

\section{PPAR $\gamma$ : The Glitazone Receptor}

Type 2 diabetes is characterized by a resistance of peripheral tissues including skeletal muscle, liver, and adipose - to the actions of insulin. The development of insulin resistance is an early event in the progression of type 2 diabetes. In the early 1980s, scientists at the Japanese pharmaceutical company Takeda reported the first of a promising new class of thiazolidinedione-based antidiabetic compounds, termed glitazones (Sohda et al., 1982). These molecules lowered glucose levels in rodent models of insulin resistance without increasing insulin secretion from the pancreas, hence, their designation of insulin sensitizers. The glitazones originally were derived from the fibrate clofibrate, which was noted to have weak antihyperglycemic activity in rodents. Optimization of the glucose-lowering activity of clofibrate through a combination of traditional medicinal chemistry and in vivo pharmacology yielded the prototypical glitazone, ciglitazone. In addition to its antihyperglycemic effects, ciglitazone reduced levels of insulin and lipids, including both triglycerides and nonesterified fatty acids. Subsequent optimization of these glitazone activities in animal models led to more-potent members of this chemical class, including troglitazone, pioglitazone, and rosiglitazone (Figure 2) (Spiegelman, 1998). Rosiglitazone and pioglitazone are currently approved for use for type 2 diabetes under the trade names Avandia $^{\mathrm{TM}}$ and Actos ${ }^{\mathrm{TM}}$, respectively. Troglitazone (Rezulin ${ }^{\mathrm{TM}}$ ), the first of the glitazones approved by the U.S. Food and Drug Administration, was recently removed from the market due to idiosyncratic hepatotoxicity, which in extreme cases caused liver failure.

In 1995, we reported that PPAR $\gamma$ was the receptor for the glitazones (Lehmann et al., 1995). Two seemingly disparate bodies of literature led us to test whether glitazones might modulate PPAR $\gamma$ activity. First, PPAR $\gamma$ was shown to be highly expressed in adipocytes (Chawla et al., 1994; Tontonoz et al., 1994a) and to serve as a critical regulator of fat cell differentiation in vitro. Ectopic expression of PPAR $\gamma$ in fibroblasts in the presence of weak PPAR $\gamma$ activators resulted in their efficient differentiation into mature adipocytes (Tontonoz et al., 1994b). Second, the glitazones had been reported to dramatically enhance insulin-dependent differentiation of various preadipocyte and stem cell lines to fat cells (Hiragun et al., 1988; Sparks et al., 1991). Among the genes regulated by glitazones in fat cells was the adipocyte fatty acid-binding protein aP2, a gene that is regulated directly by PPAR $\gamma$ (Kletzein et al., 1992; Harris and Kletzien, 1994; Tontonoz et al., 1994a). We initially demonstrated that glitazones were selective activators of PPAR $\gamma$ in transfection assays and bound directly to the receptor 
(Lehmann et al., 1995). We subsequently showed that the potencies of glitazones in binding and activating PPARy in vitro correlated closely with their glucoselowering activities in vivo (Willson et al., 1996). Taken together, these findings provided compelling evidence that PPAR $\gamma$ was the molecular target for the antidiabetic actions of the glitazones. At first glance, it appeared counterintuitive that a key regulator of fat cell differentiation would be the molecular target for these antidiabetic drugs. However, work from a number of laboratories using a variety of experimental approaches has confirmed that PPAR $\gamma$ is, indeed, the molecular target for the antidiabetic actions of the glitazones (Spiegelman, 1998).

The glitazones were developed in rodent models of insulin resistance in the absence of any knowledge about their molecular target. Moreover, the glitazones contain a chiral center at carbon 5 of the thiazolidinedione headgroup but have been developed as a mixture of isomers (racemates), since they undergo racemization in vivo. Having the knowledge of their molecular target, we quickly established that only the (S)-enantiomers of the glitazones bind with high affinity to PPAR $\gamma$ (Nolte et al., 1998; Parks et al., 1998; Gampe et al., 2000; Willson et al., $2000 \mathrm{~b}$ ). Thus, only 50 percent of the drug substance in the currently approved glitazones is likely to be active. We also found that one of the glitazones, troglitazone, has significant activity on the nuclear receptor PXR, a key transcriptional regulator of CYP3A expression in the liver and intestine (Jones et al., 2000). Consistent with this observation, troglitazone was reported to interact with drugs metabolized by CYP3A (e.g., oral contraceptives). Over the last 5 years, our group has focused much of its effort on the identification of antidiabetic drugs optimized for their activity on PPAR $\gamma$. Recently, we reported a series of tyrosine-based PPAR $\gamma$ agonists - including GI 262570, GW 1929, and GW 7845 - that fulfill these criteria (Figure 2) (Cobb et al., 1998; Collins et al., 1998; Henke et al., 1998; Brown et al., 1999). These compounds are single enantiomers synthesized from the amino acid L-tyrosine and are extremely potent PPAR $\gamma$ agonists, binding to the receptor at low nanomolar concentrations. Moreover, these PPAR $\gamma$ agonists do not activate PXR. Importantly, GW 1929 was shown to lower glucose levels in Zucker diabetic fatty (ZDF) rats at serum plasma concentrations more than 100-fold lower than troglitazone, which mirrors the differences in the potencies of these two compounds at PPAR $\gamma$ in vitro (Brown et al., 1999). One of these compounds, GI 262570, has subnanomolar activity on human PPAR $\gamma$ and submicromolar activity on PPAR $\alpha$. GI 262570, currently in phase III of clinical trials for the treatment of type 2 diabetes, represents the first PPAR agonist optimized against the human receptor to be progressed into the clinic. Early clinical data indicate that GI 262570 has potent glucose-lowering effects and also lowers triglycerides and raises HDL cholesterol in diabetes patients (Fiedorek et al., 2000; Wilson et al., 2000). 
Although it is clearly established that PPAR $\gamma$ modulates insulin sensitivity, a paradox remains: how does activation of a nuclear receptor that is highly expressed in fat sensitize skeletal muscle and liver to the actions of insulin? We now believe that several plausible explanations exist. First, PPAR $\gamma$ may regulate signaling molecules that are secreted from adipose and affect glucose utilization and/or production in other tissues. Examples of signaling molecules that are secreted by adipocytes and affect energy balance are tumor necrosis factor $\alpha$ $(\mathrm{TNF} \alpha)$ and leptin. Expression of both these genes is repressed by PPAR $\gamma$ agonists (Hofmann et al., 1994; De Vos et al., 1996; Kallen and Lazar, 1996). A second possibility is that the effects of PPAR $\gamma$ agonists on glucose utilization are secondary to those on fatty acids. High circulating levels of fatty acids are known to interfere with glucose utilization in skeletal muscle through the Randle cycle and to promote glucose production in the liver (Randle, 1998). PPAR $\gamma$ agonists reduce serum concentrations of both esterified and nonesterified fatty acids, presumably by promoting their uptake and storage in adipocytes. Finally, PPAR $\gamma$ is expressed, albeit at low levels, in both skeletal muscle and liver. Thus, PPAR $\gamma$ agonists may have direct effects on glucose utilization or production in both of these tissues.

In order to better understand the mechanisms underlying the antidiabetic actions of PPAR $\gamma$ agonists, we recently used a comprehensive mRNA-profiling technique to identify PPAR $\gamma$ target genes in insulin-sensitive tissues of an animal model of type 2 diabetes. ZDF rats, a standard animal model of type 2 diabetes, were treated for 7 days with either the potent, selective PPAR $\gamma$ agonist GW 1929 or with vehicle alone. Genes that were regulated in response to PPAR $\gamma$ agonist in epididymal white adipose tissue (WAT), interscapular brown adipose tissue (BAT), liver, and soleus skeletal muscle were identified using CuraGen Corporation's GeneCalling TM technology (Shimkets et al., 1999). We observed the coordinated upregulation of a number of genes involved in fatty acid transport, storage, and oxidation in both WAT and BAT from PPARy agonist-treated rats. By contrast, a subset of these genes was coordinately downregulated in skeletal muscle upon treatment. Notably, we observed a marked decrease in pyruvate dehydrogenase kinase 4 (PDK4) expression in muscle from GW 1929-treated rats. PDK4 phosphorylates pyruvate dehydrogenase (PDH) and inhibits the activity of this mitochondrial enzymatic complex, which catalyzes the first irreversible step in glucose oxidation (Randle, 1998). Interestingly, decreased PDH activity and increased PDK activity are associated with insulin resistance and type 2 diabetes (Majer et al., 1998; Sreenan et al., 1999). Thus, the decreases that we observe in PDK4 activity may be an important component of the insulin-sensitizing activity of PPAR $\gamma$ agonists in skeletal muscle. In liver, PPAR $\gamma$ agonist treatment resulted in decreased expression of phosphoenolpyruvate carboxykinase, which encodes the rate-limiting step in hepatic gluconeogenesis. These findings are consistent 
with reports that glitazones reduce gluconeogenesis in patients with type 2 diabetes. Overall, the gene-expression patterns suggest that PPAR $\gamma$ agonists promote a flux of fatty acids into adipose tissue and away from skeletal muscle and liver. Decreased fatty acid metabolism in muscle is likely to account in large measure for increased glucose utilization via the Randle cycle (Randle, 1998). At the same time, decreases in fatty acid levels in the liver may account for reduced glucose production (Randle, 1998). Our data provide evidence that the antidiabetic actions of PPAR $\gamma$ agonists are the consequence of coordinate regulation of gene expression in multiple insulin-sensitive tissues (Figure 3). However, it remains to be determined whether the effects of PPAR $\gamma$ agonists in skeletal muscle and liver are mediated directly through activation of PPAR $\gamma$ in these tissues or are the indirect consequence of PPAR $\gamma$ activation in adipocytes.

\section{PPAR $\delta$}

Much less is known about the biology of PPAR $\delta$ than either of the other two PPAR subtypes. It seems likely that PPAR $\delta$ is involved in lipid metabolism, since fatty acids activate the receptor (see below). Fibroblasts transfected with a PPAR $\delta$

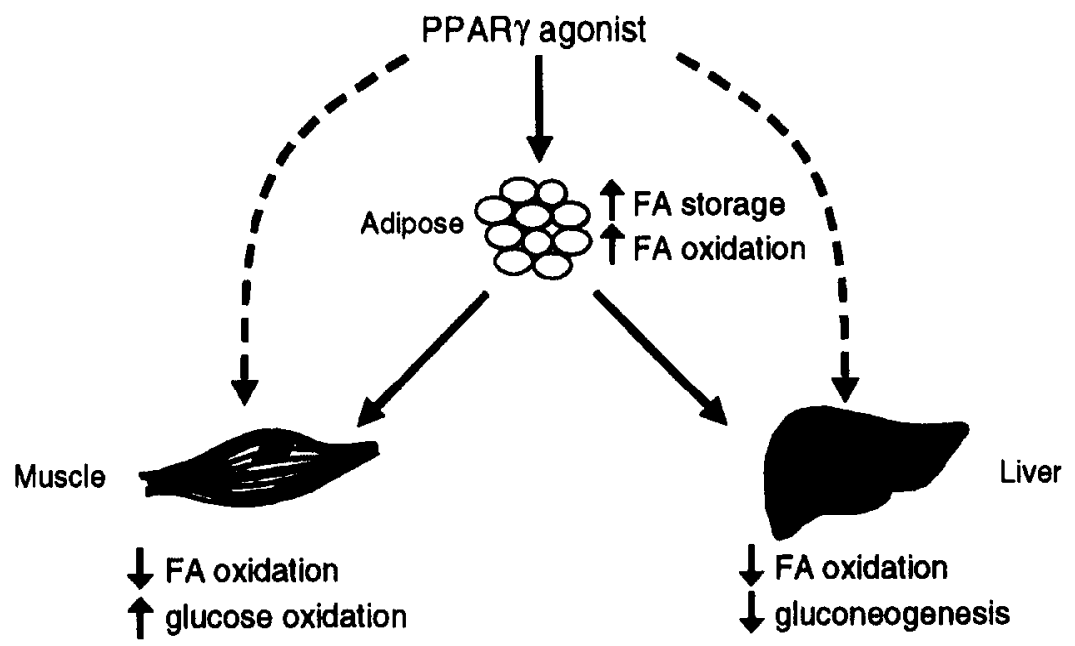

FIG. 3. Model for the insulin-sensitizing actions of PPAR $y$ agonists. PPARy agonists regulate genes in fat cells, resulting in a flux of fatty acids into adipocytes, where they are stored or metabolized, and away from skeletal muscle and liver (solid arrows). The net effect of this fatty acid repartitioning is an increase in glucose oxidation in muscle and a decrease in glucose production by the liver. PPAR $y$ agonists also may have direct effects on gene expression in muscle and liver (dotted arrows). 
expression vector become responsive to fatty acids, as measured by the induction of early genes in the adipocyte differentiation cascade (Bastie et al., 1999). In support of this idea, the Gonzalez laboratory recently reported that mice lacking functional PPAR $\delta$ have reduced adipose tissue stores compared to control animals (Peters et al., 2000). The PPAR $\delta$-null mice are smaller than control animals and display myelination defects in the corpus callosum and enhanced hyperplasia of the epidermis in response to the phorbol ester O-tetradecanoylphorbol-13-acetate (TPA). These findings establish roles for PPAR $\delta$ in development and in brain and skin function. The spectrum of defects observed in the PPAR $\delta$-null mice is consistent with the broad expression pattern of this PPAR subtype.

Unlike PPAR $\alpha$ and PPAR $\gamma$, no drugs have been identified that work through PPAR $\delta$. Moreover, the synthetic PPAR $\delta$ ligands that have been reported to date lack either potency or selectivity or both. Thus, a major challenge in unraveling the biology of PPAR $\delta$ is to identify the appropriate chemical tools. Through solid-phase synthesis of a combinatorial library of fibrate analogs, we identified several compounds that activated human PPAR (Brown et al., 1997). GW 2433 (Figure 2) was the most-potent activator of PPAR $\delta$ in this series, although it showed only modest selectivity over PPAR $\alpha .\left[{ }^{3} \mathrm{H}\right] \mathrm{GW} 2433$ bound to PPAR $\delta$ with a $\mathrm{K}_{\mathrm{i}}$ of $40 \mathrm{nM}$ and has been employed as a radioligand to aid in the development of selective PPAR $\delta$ agonists. Interestingly, scientists at Merck demonstrated that the leukotriene antagonist L-16504l activated PPAR $\delta$ and raised serum cholesterol levels in $\mathrm{db} / \mathrm{db}$ mice (Berger et al., 1999). Although this compound is not selective for murine PPAR $\delta$ over murine PPAR $\gamma$, the pharmacological effect was attributed to activation of PPAR $\delta$, since neither serum glucose nor triglycerides were lowered at the same dose. These data suggest that PPAR $\delta$, like the other two PPAR subtypes, may have important roles in lipid metabolism.

\section{Natural PPAR Ligands}

Although synthetic ligands, including the fibrates and glitazones, have provided a great deal of insight into PPARs, a comprehensive understanding of PPAR physiology requires the identification of their natural ligands. The Gustafsson laboratory was the first to show that PPAR $\alpha$ is activated by micromolar concentrations of a surprisingly diverse collection of fatty acids that vary in both chain length and degree of saturation (Gottlicher et al., 1992). A search for natural PPAR $\alpha$ ligands in fractionated human serum identified palmitic acid, oleic acid, linoleic acid, and arachidonic acid as naturally occurring activators of this orphan receptor (Figure 4) (Banner et al., 1993). Subsequent work showed that fatty acids also activate PPAR $\gamma$ and PPAR $\delta$. Given their important role in energy balance, the idea that the PPARs might serve as fatty acid receptors was attractive. How- 

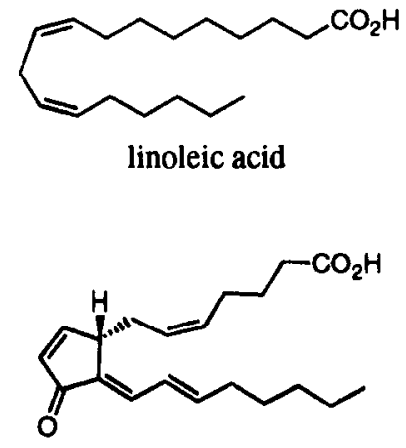

15-deoxy- $\Delta^{12,14}-\mathrm{PGJ}_{2}$

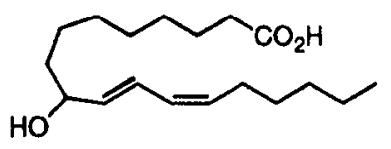

9-HODE

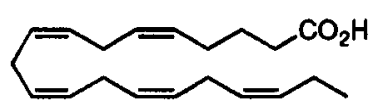

eicosapentaenoic acid

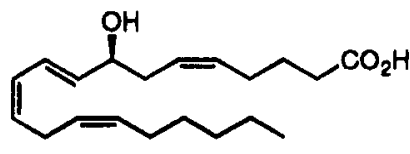

8(S)-HETE

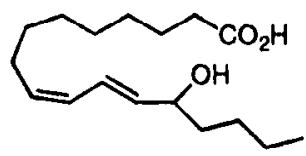

13-HODE

FIG. 4. Chemical structures of natural PPAR ligands.

ever, the relative lack of potency and biophysical properties of fatty acids had made them unsuitable for use in ligand-binding assays. Thus, it had remained unclear whether the fatty acids regulate the activity of PPARs by binding directly to them or via an indirect mechanism.

The availability of high-affinity, synthetic radioligands for all three of the PPAR subtypes provided us with the opportunity to address whether fatty acids bind directly to the PPARs. We tested a large number of saturated and unsaturated fatty acids for their ability to displace radioligands in competition binding assays. We found that many of these structurally diverse fatty acids interact directly with the PPARs at concentrations in the low micromolar range (Xu et al., 1999). Although these concentrations are higher than those typically required for ligands to bind to their cognate nuclear receptors, they are consistent with the levels of nonesterified fatty acids found in human serum. Interestingly, the three PPAR subtypes have different fatty acid-binding profiles. PPAR $\alpha$ is the most-promiscuous subtype, interacting efficiently with both saturated and unsaturated fatty acids. By contrast, PPAR $\gamma$ is the most-selective subtype, interacting efficiently with only a subset of the polyunsaturated fatty acids, including eicosapentaenoic (EPA) and arachidonic acid. PPAR $\delta$ binds to both unsaturated and saturated fatty acids but 
with slightly lower affinity than PPAR $\alpha$. Thus, the PPARs are capable of interacting with multiple fatty acids in vitro.

Certain oxidized fatty acid metabolites have been shown to function as PPAR ligands in vitro. Two of these eicosanoids, 15-deoxy $-\Delta^{12,14}$-prostaglandin $\mathrm{J}_{2}(15 \mathrm{~d}$ $\mathrm{PGJ}_{2}$ ) and $8(\mathrm{~S})$-hydroxyeicosatetraenoic acid (8(S)-HETE) (Figure 4), were found to be slightly more-potent activators of the PPARs than their polyunsaturated fatty acids precursors (Forman et al., 1995; Kliewer et al., 1995; Yu et al., 1995). These results were surprising, given that eicosanoids are known to mediate many of their biological effects through interactions with $\mathrm{G}$ protein-coupled cell-surface receptors. Interestingly, $15 \mathrm{~d}-\mathrm{PGJ}_{2}$ and $8(\mathrm{~S})$-HETE were subtype-selective in their interactions with the PPARs. Whereas $15 \mathrm{~d}-\mathrm{PGJ}_{2}$ was selective for PPAR $\gamma, 8(\mathrm{~S})$ HETE interacted preferentially with $\operatorname{PPAR} \alpha$. More recently, the lipoxygenase products 9-hydroxyoctadecadienoic acid (HODE), 13-HODE, and 15-HETE (Figure 4), which are components of oxidized LDL, were shown to bind and activate both PPAR $\alpha$ and PPAR $\gamma$ (Nagy et al., 1998; Huang et al., 1999; Delerive et al., 2000 ). There is also evidence to suggest that prostacyclin is a natural ligand for PPAR $\delta$. Mice lacking cyclooxygenase 2 (COX2), which is involved in prostacyclin biosynthesis, are impaired for blastocyst implantation in the uterus during pregnancy (Lim et al., 1999). Expression of both PPAR $\delta$ and prostacyclin synthase is induced in the stroma surrounding the blastocyst during implantation. Notably, PPAR $\delta$ ligands, including the stable prostacyclin analog carbaprostacyclin, restore implantation in the COX2-deficient mice (Lim et al., 1999). Although prostacyclin is too unstable to test in standard PPAR $\delta$-binding assays, these data raise the possibility that this prostanoid is a PPAR $\delta$ ligand in vivo. Thus, the regulated conversion of polyunsaturated fatty acids to eicosanoids through either the cyclooxygenase or lipoxygenase pathways may provide a mechanism for modulating the activities of one or more of the PPAR subtypes.

The discovery that the PPARs are capable of binding to a variety of fatty acids and their metabolites suggests that their activation in vivo may not determined through interactions with a single, high-affinity ligand like the classical steroid hormone and retinoid receptors, but rather through interactions with a number of fatty acids and fatty acid metabolites. Thus, the PPARs may function as generalized sensors of fatty acid levels, coupling fluxes in the levels of these fatty acids to the transcriptional regulation of genes involved in lipid and glucose homeostasis. In this regard, it is interesting that several other orphan nuclear receptors, including FXR and the LXRs, also bind to their natural oxysterol and bile acid ligands at low micromolar concentrations (Repa and Mangelsdorf, 1999). Thus, many of the orphan nuclear receptors may function as metabolic sensors. However, this idea remains controversial and the search for high-affinity PPAR ligands continues. 


\section{A Structural Basis for PPAR Promiscuity and Permissiveness}

As receptors for various fatty acids and fatty acid metabolites, the PPARs are much more promiscuous in terms of their interactions with ligands than other members of the nuclear receptor family. Recent x-ray crystal structures of the PPAR $\gamma$ and PPAR $\delta$ LBDs in either the absence or presence of ligand have provided tremendous insight into the molecular basis for the unusual ligand-binding properties of the PPARs. The structures of the PPAR LBDs are composed of $13 \alpha$ helices and a small, four-stranded $\beta$ sheet, which fold to form a "helical sandwich" (Figure 5A) (Nolte et al., 1998; Uppenberg et al., 1998; Xu et al., 1999; Gampe et al., 2000). The overall fold of the PPAR LBDs is similar to that of other nuclear receptors from helix 3 to the C-terminus. However, the PPARs are unique in having an additional helix, termed helix $2^{\prime}$, present between helices 2 and 3. A striking feature of the PPAR LBDs is the very large volume of their hydrophobic, ligand-binding cavities (Figure 5A). The solvent-accessible cavities of both the apo PPAR $\gamma$ and PPAR $\delta$ LBDs are over $1000 \AA^{3}$ in volume, which is approximately three times larger than those of other nuclear receptors for which the structure has been determined. This large volume is due in large part to the presence of helix $2^{\prime}$ and the position of helix 2 , which effectively wedge open the ligand-binding pocket. The positioning of these helices also results in a $100 \AA^{2}$ channel through which ligands can enter the pocket. The presence of a very-flexible loop between helices $2^{\prime}$ and 3 suggests that the channel opening has the potential to be even bigger. This mode of ligand entry appears to be unique to the PPARs. The structures of the other nuclear receptors determined to date including steroid, retinoid, and thyroid hormone receptors - suggest that their ligands enter the binding cavity on the other side of the protein through a channel formed by helices 3,4 , and 10 and capped by the AF-2 helix in the ligand-bound conformation.

The structure of the PPAR $\gamma$ LBD was solved more recently as a six-component complex with the LBD of RXR $\alpha$, an antidiabetic drug, the RXR $\alpha$ ligand, 9-cis retinoic acid, and two peptide fragments of steroid receptor coactivator-1 (SRC-1) (Gampe et al., 2000). Overall, the complex is shaped like a butterfly, with both PPAR $\gamma$ and RXR $\alpha$ adopting the helical sandwich fold that is conserved among nuclear receptors. The PPAR $\gamma / \mathrm{RXR} \alpha$ dimerization interface is comprised of a complex network of hydrophobic and polar interactions mediated by helices 7,9 , and 10 and the loop between helices 8 and 9 of each receptor. The residues of PPAR $\gamma$ that are involved in these interactions are highly conserved in other nuclear receptors that heterodimerize with RXR $\alpha$. Notably, the PPAR $\gamma / R X R \alpha$ dimerization interface is asymmetric, with each LBD tilted approximately $10^{\circ}$ from the $\mathrm{C} 2$ axis of symmetry. This asymmetry results in additional, unexpected interactions between $\operatorname{PPAR} \gamma$ and $\operatorname{RXR} \alpha$, including the packing of a negatively 
A

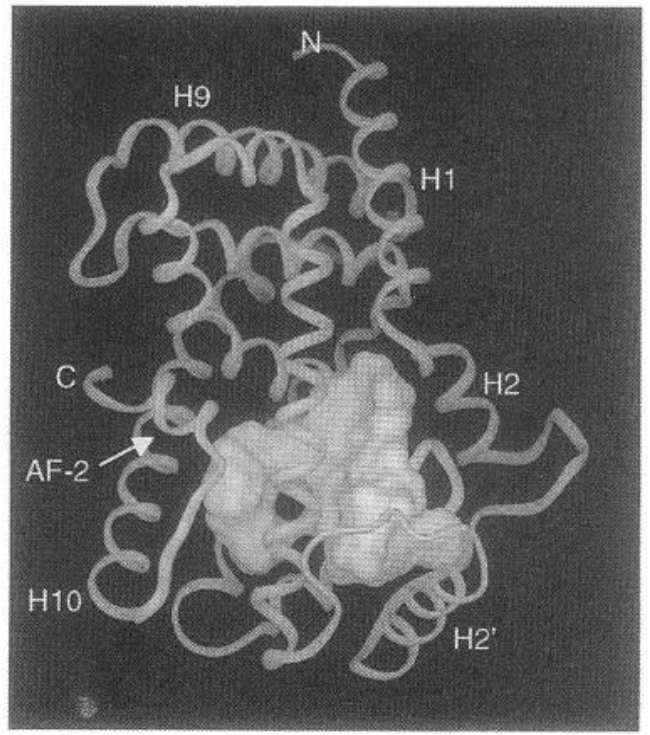

B

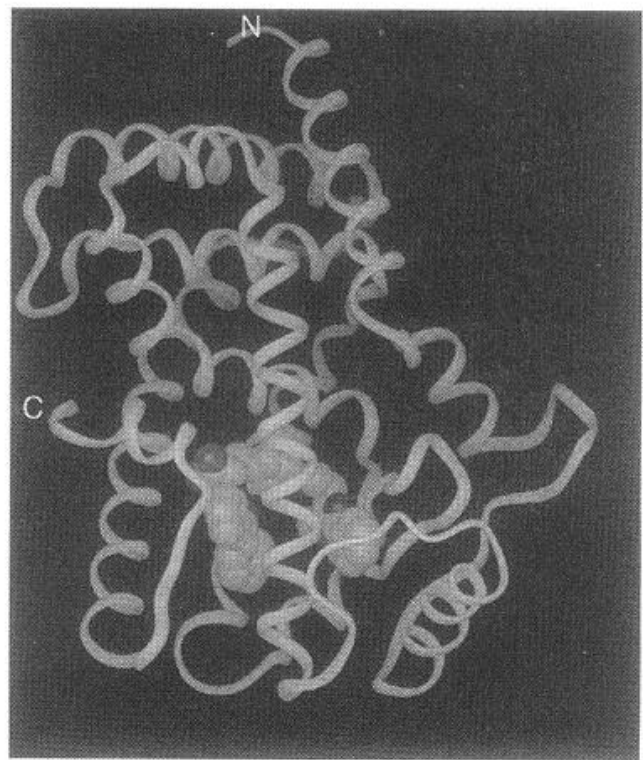

FIG. 5. PPAR $\gamma$ LBD crystal structures. (A) PPAR $\gamma$ LBD crystal structure with the solvent-accessible, ligand-binding cavity highlighted. The carboxy $(\mathrm{C})$ and amino $(\mathrm{N})$ termini and selected helices are indicated. (B) Crystal structure of the antidiabetic drug GI 262570 bound to the PPAR $\gamma$ LBD. 
charged surface of PPAR $\gamma$ composed of the end of the AF-2 helix and the loop between helices 8 and 9 against a positively charged region of RXR $\alpha$ helix 7 . These additional interactions increase the total area of the dimerization interface from roughly $500 \AA^{2}$ to $550 \AA^{2}$, which accounts in large measure for the preference of PPAR $\gamma$ and $R X R \alpha$ to form heterodimers rather than their respective homodimers.

The antidiabetic, insulin-sensitizing drugs GI 262570 or rosiglitazone bind into the large hydrophobic pocket of the PPAR $\gamma$ subunit of the heterodimer in a U-shaped conformation around helix 3 . There, they are stabilized by numerous hydrophobic interactions between the lipophilic portion of the molecule and the ligand-binding pocket (Figure 5B). Moreover, the carboxylic acid of GI 262570 and the thiazolidinedione headgroup of rosiglitazone make essentially the same network of hydrogen bonds with residues in PPAR $\gamma$, including Y473 in the AF-2 helix and $\mathrm{H} 323$ and $\mathrm{H} 449$ in helices 5 and 10, respectively. This pattern of hydrogen bonding effectively stabilizes the AF-2 domain of PPAR $\gamma$ in a conformation that is permissive for interaction with SRC-1. The peptide fragments of SRC-1 each contain an LXXLL motif, which adopts an $\alpha$-helical conformation when bound to the PPAR $\gamma$ LBD. The leucine residues of the LXXLL motif pack into a hydrophobic groove formed by helices 3, 4, and AF-2 of the PPAR $\gamma$ LBD, with the ends of the helix stabilized by salt bridges with E471 in the AF-2 helix and $\mathrm{K} 301$ in helix 3. The residues that comprise this groove as well as E471 and $\mathrm{K} 301$ are highly conserved among members of the nuclear receptor superfamily, suggesting a common mechanism underlying ligand-mediated recruitment of coactivator proteins.

Although many similarities exist in the binding of GI 262570 and rosiglitazone to PPAR $\gamma$, there are also important differences. Whereas GI 262570 occupies about 40 percent of the ligand-binding cavity, rosiglitazone occupies only about 25 percent of the pocket. The benzophenone group attached to the tyrosine nitrogen of GI 262570 reaches approximately $7 \AA$ into a hydrophobic cavity formed by helices 3,7 , and 10 . These hydrophobic interactions made by the benzophenone group of GI 262570 are not available to rosiglitazone or other glitazones. At its other end, the phenyloxazole tail of GI 262570 is inserted approximatley $2.3 \AA$ deeper into a cleft formed by helices 6 and 7 in the ligandbinding pocket than is the corresponding hydrophobic tail of rosiglitazone. The additional hydrophobic interactions between GI 262570 and both ends of the PPAR $\gamma$ ligand-binding pocket provide a molecular basis for the nearly 50-fold increase in potency of this antidiabetic agent, relative to rosiglitazone.

The PPAR $\gamma / \mathrm{RXR} \alpha$ complex is activated efficiently by ligands for both the PPAR $\gamma$ and RXR $\alpha$ subunits of the heterodimer. As a consequence, RXR ligands have many of the same biological actions as PPAR $\gamma$ ligands, including the glucose 
and lipid-lowering effects in rodent models of type 2 diabetes (Mukherjee et al., 1997). The asymmetric interactions between the AF-2 helix of PPAR $\gamma$ and helices 7 and 10 of $\operatorname{RXR} \alpha$ in the heterodimer suggest an unexpected basis for the permissive activation of this complex by RXR ligands. The net effect of these interactions may be the stabilization of the PPAR $\gamma$ AF-2 helix in a "quasi-active" position that is permissive for interactions with coactivator proteins, even in the absence of a PPAR $\gamma$ agonist. Assuming that two coactivator interfaces are required for stable receptor-coactivator interactions and transcriptional activation, the binding of an agonist to the RXR $\alpha$ component of the heterodimer may be sufficient to form the second interface and activate the complex. The addition of a PPAR $\gamma$ agonist would be expected to further increase the stability of this activated complex. Thus, the asymmetric nature of the PPAR $\gamma / \mathrm{RXR} \alpha$ dimerization interface also may explain the additive or synergistic effects that have been reported between PPAR $\gamma$ and RXR agonists.

Comparing the PPAR $\gamma$ and $R X R \alpha$ complexes within the heterodimer with their respective apo structures reveals important differences in the mechanism of activation of these receptors. The apo RXR $\alpha$ LBD and the ligand-bound RAR $\gamma$ LBD were the first nuclear receptor LBDs to be solved by $x$-ray crystallography (Bourguet et al., 1995; Renaud et al., 1995). Comparison of these structures led to the dogma that all nuclear receptors undergo a large "mouse-trap" conformational change upon ligand binding. With the apo and ligand-bound LBD structures available for both RXR $\alpha$ and PPAR $\gamma$, we were able to re-examine this hypothesis. Our structures show that $\mathrm{RXR} \alpha$ does, indeed, undergo a large conformational change upon binding of 9-cis-retinoic acid but that it may be unique among the nuclear receptors in this respect. The apo RXR $\alpha$ structure is forced to break helix 10 in order to accommodate three consecutive phenylalanine residues. This break in helix 10 drives the C-terminal AF-2 helix away from the body of the receptor but allows two of the phenylalanine residues to bury themselves in the hydrophobic core of the receptor. The binding of the RXR ligand displaces these residues from this position, which triggers the conformational change that folds the AF-2 helix against the body of the receptor.

Analysis of the PPAR $\gamma$ structures indicates a fundamentally different mechanism of activation. PPAR $\gamma$, like most nuclear receptors, does not contain three consecutive phenylalanines in helix 10. The apo PPAR $\gamma$ structure shows that there is no drive to break helix 10 . The C-terminal AF-2 helix already is folded against the body of the receptor in the unliganded state. The PPAR $\gamma / \operatorname{RXR} \alpha$ heterodimer suggests that, even in the unliganded state, the AF-2 helix will be stabilized in this "quasi-active" position by its interactions with RXR $\alpha$. In PPAR $\gamma$, the ligandbound structures reveal that the ligand plays an important role in stabilizing the AF-2 helix in the active position through a direct $\mathrm{H}$-bond between the acidic 
ligand and Tyr473 on the AF-2 helix. This tyrosine residue is conserved in PPAR $\alpha$ and PPARS. Interestingly, the other permissive nuclear receptors, FXR and LXR, have a tryptophan at this position, which might be capable of making a similar hydrogen bond with their respective natural ligands. Thus, within the PPAR $\gamma / \operatorname{RXR} \alpha$ complex, we now have evidence that there are two distinct mechanisms for activation of nuclear receptors by their ligands.

How do the PPARs interact with such a structurally diverse collection of natural fatty acids? We recently reported that the structures of PPAR $\delta$ bound to either the polyunsaturated fatty acid EPA or a fibrate, GW 2433, which binds to the receptor with high affinity $\left(K_{d}=40 \mathrm{nM}\right)(X u$ et al., 1999). The acid moieties of EPA and GW 2433 made the same intricate series of hydrogen bonds in PPAR $\delta$ that GI 262570 makes in PPAR $\gamma$, stabilizing the AF-2 helix in a conformation permissive for coactivator interactions. The conservation of this hydrogen bond network further confirms that it must be crucial for ligand-mediated activation of the PPARs. Remarkably, the PPAR $\delta$ ligand-binding cavity is sufficiently large to allow the long lipophilic tail of EPA to bind in two completely different conformations, which we designated "tail up" and "tail down" (Figure 6). In the tail-up conformation, the hydrophobic tail of EPA was bent up into the upper portion of the ligand-binding pocket. EPA was completely buried within the pocket in this conformation. In the second binding mode, the tail of EPA was bent down into the lower region of the ligand-binding cavity. EPA was partially exposed to solvent via the open channel in the tail-down conformation. In each docking mode, EPA occupied approximately $300 \AA^{3}$, which is only about 30 percent of the total accessible volume of the hydrophobic pocket. Notably, the fibrate GW 2433 bound to PPAR $\delta$ in a manner such that it occupied essentially the same space as EPA bound in both of its binding modes. The large number of hydrophobic interactions between GW 2433 and PPAR are likely to account for the increased potency of this ligand relative to EPA.

The $\mathrm{x}$-ray crystal structures provide a molecular explanation for the ability of the PPARs to interact with a structurally diverse set of amphipathic acids. First, the acid moieties of PPAR ligands, including thiazolidinediones and carboxylic acids, make an intricate series of hydrogen bonds with the receptor that includes the conserved tyrosine in the AF-2 helix. These hydrogen bonds stabilize the PPARs in a conformation that is permissive for coactivator interactions. This mode of ligand binding is different from that of the retinoic acid and thyroid hormone receptors, in which the carboxylic acids of the ligands are positioned in the interior of the hydrophobic cavity, away from the AF-2 helix. Second, the hydrophobic pockets of the PPARs are sufficiently large to allow the hydrophobic tails of their ligands to bind in multiple conformations, providing a basis for the promiscuous binding properties of the PPARs. The PPAR $\delta$-EPA structure explains why the PPARs bind only to fatty acids of certain chain lengths. Short fatty 


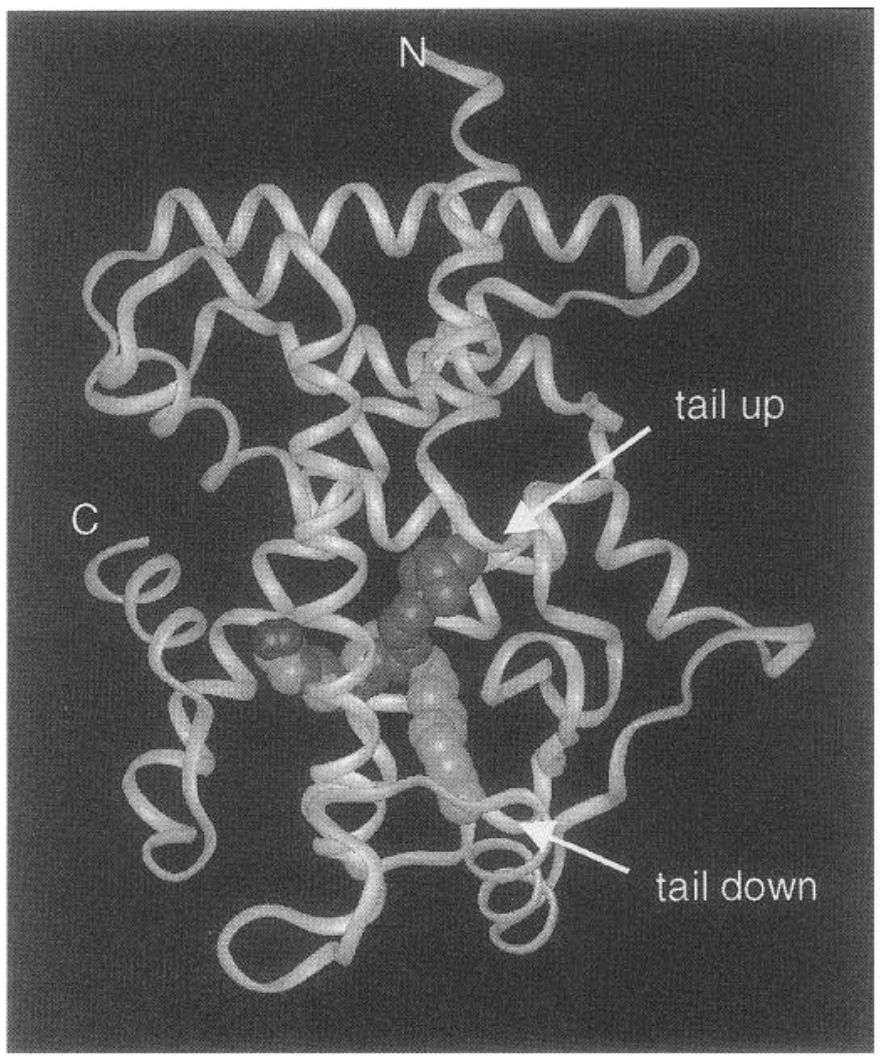

FIG. 6. Crystal structure of PPAR $\delta$ bound to the fatty acid EPA. The two different conformations of EPA seen in the crystal structure are indicated as "tail up" and "tail down."

acids $(C<14)$ could not make the hydrophobic interactions necessary for stable ligand binding. In contrast, long-chain fatty acids $(C>20)$ could not fit into the pocket in either binding mode and would be exposed to the destabilizing effects of the solvent. We suggest that the PPARs may have evolved their unique structures in order to detect a variety of different fatty acids and/or fatty acid metabolites and to regulate transcription accordingly.

\section{Selective PPAR $\gamma$ Modulators}

Synthetic antagonists have been identified for a number of the nuclear receptors that counter the effects of hormones. Notable examples include the antipro- 
gestin and antiglucocorticoid RU486, the antimineralocorticoid spironolactone, and the antiestrogens tamoxifen and raloxifene. Not only have these antagonists been useful tools for the dissection of nuclear reccptor signaling pathways but they also have important pharmacologic activities that make them useful for the treatment of various diseases or physiological conditions. Recent $x$-ray crystal structures of the estrogen receptor bound to either tamoxifen and raloxifene reveal that these antagonists bind into the ligand-binding pocket in such a way as to force the AF-2 helix into a conformation that prevents coactivator interactions (Brzozowski et al., 1997; Shiau et al., 1998).

The large volume of the PPAR ligand-binding cavities suggested that it might be possible to identify novel classes of ligands that bind to these receptors without activating them. We recently identified a nonthiazolidinedione acetamide, designated GW 0072 (Figure 2), that bound to PPAR $\gamma$ with high affinity $\left(\mathrm{K}_{\mathrm{i}}=70 \mathrm{nM}\right)$ (Oberfield et al., 1999). However, unlike other PPAR $\gamma$ ligands, GW 0072 was only a very weak partial agonist of PPAR $\gamma$, activating the full-length PPAR $\gamma$ with only about 15 percent of the efficacy of rosiglitazone and other PPAR $\gamma$ full agonists. Consistent with its weak transcriptional activity, GW 0072 did not promote efficient interactions between PPAR $\gamma$ and various coactivator proteins. Moreover, GW 0072 was able to effectively antagonize the recruitment of coactivators induced by rosiglitazone. Thus, the low efficacy of GW 0072 in transfection assays was paralleled by its inability to recruit coactivator proteins.

As already noted, efficacious PPAR $\gamma$ agonists promote the differentiation of various preadipocyte and stem cell lines into mature adipocytes. To further characterize the activities of GW 0072, we profiled its effects on the differentiation of $10 \mathrm{~T} 1 / 2$ cells to adipocytes. As expected, treatment of $10 \mathrm{~T} 1 / 2$ cells with rosiglitazone resulted in their efficient differentiation, as measured by the accumulation of neutral lipid droplets and expression of an adipocyte-specific pattern of gene expression. By contrast, treatment of 10T1/2 cells with GW 0072 resulted in very little conversion of the cells to mature adipocytes. Notably, GW 0072 completely blocked rosiglitazone-induced adipocyte differentiation. Thus, GW 0072 represents a novel class of high-affinity PPAR $\gamma$ ligands that can block glitazone-induced adipocyte differentiation in vitro.

In order to understand precisely how GW 0072 antagonized PPAR $\gamma$ activity, the co-crystal structure of GW 0072 bound to PPAR $\gamma$ was solved. Remarkably, GW 0072 bound exclusively in the righthand portion of the pocket bounded by helices 3, 6, and 7 (Figure 7) (Oberfield et al., 1999). Unlike the other PPAR ligands studied, the carboxylic acid of GW 0072 did not interact with the AF-2 helix or the adjacent histidine residues but was instead embedded in the loop separating helices $2^{\prime}$ and 3 . Residues Y473, H449, and H323, which make the network of hydrogen bonds that tether the AF-2 helix in the active configuration in the presence of full agonists, adopted positions similar to the apo PPAR $\gamma$ crystal 


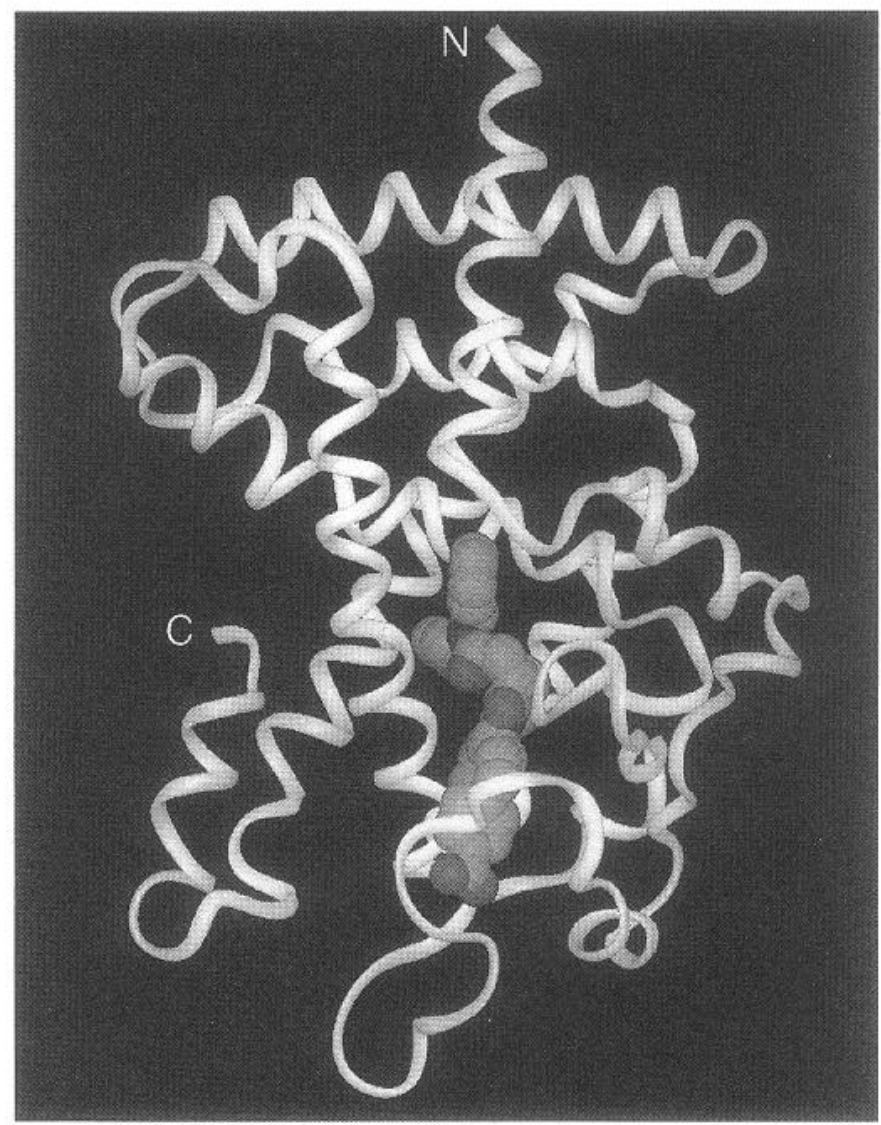

FIG. 7. Crystal structure of the partial agonist GW 0072 bound to the PPAR $\gamma$ LBD. GW 0072 is bound in the righthand portion of the LBD and does not interact with the AF-2 helix.

structure. These data suggest that GW 0072 binding results in a PPAR $\gamma$ conformation that is not permissive for the recruitment of coactivator proteins. Although GW 0072 is only a weak PPAR $\gamma$ agonist in vitro, it maintains many of the in vivo effects of full PPAR $\gamma$ agonists. For example, in insulin-resistant, nondiabetic Zucker fatty rats, GW 0072 showed equivalent efficacy to the tyrosine agonist GW 7845 for lowering insulin levels. Interestingly, in contrast to GW 7845, GW 0072 did not cause weight gain in these animals. These results raise the intriguing possibility the PPAR $\gamma$ modulators could be developed that maintain the antidiabetic properties of the glitazone drugs while reducing some of their adverse effects on weight gain. 


\section{Summary}

Over 30 years of classical pharmacology and medicinal chemistry have contributed to our understanding of the PPARs. These studies began with the synthesis of clofibrate as a metabolically stable fatty acid mimic with triglyceride-lowering activity. This, in turn, led to the synthesis of the glitazones as fibrate analogs with improved glucose-lowering activity. These advances laid the foundation for the discovery of PPAR $\alpha$ and PPAR $\gamma$ as the molecular targets for the fibrates and glitazones, respectively. We have now completed the first lap of this chemical excursion by demonstrating that a variety of natural fatty acids and fatty acid metabolites serve as PPAR ligands. The unique structure of the PPARs allows them to bind to this structurally diverse collection of natural and synthetic molecules and suggests that these ligand-activated transcription factors evolved as the body's fatty acid sensors in order to couple fatty acid levels to glucose and lipid homeostasis. Among the significant challenges that remain are the elucidation of the biological role of PPAR $\delta$ and the identification of selective PPAR modulators that maximize therapeutic effects and minimize detrimental side effects. As we begin the new millennium, we are confident that the intense research into the PPARs will continue to generate exciting new insights into human physiology and to yield new generations of safer and more-effective drugs for the treatment of atherosclerosis, dyslipidemia, type 2 diabetes, and other medical disorders.

\section{ACKNOWLEDGMENTS}

We thank our many colleagues at Glaxo Wellcome for their contributions to the work presented in this review. We acknowledge Jim Way, Wally Harrington, and Kathleen Brown for communicating unpublished results.

\section{REFERENCES}

Banner, C.D., Gottlicher, M., Widmark, E., Sjovall, J., Rafter, J.J., and Gustafsson, J.A. (1993). J. Lipid Res. 34, 1583-1591.

Bastie, C., Holst, D., Gaillard, D., Jehl-Pietri, C., and Grimaldi, P.A. (1999). J. Biol. Chem. 274, 21920-21925.

Berger, J., Leibowitz, M.D., Doebber, T.W., Elbrecht, A., Zhang, B., Zhou, G., Biswas, C., Cullinan, C.A., Hayes, N.S., Li, Y., Tanen, M., Ventre, J., Wu, M.S., Berger, G.D., Mosley, R., Marquis, R., Santini, C., Sahoo, S.P., Tolman, R.L., Smith, R.G., and Moller, D.E. (1999). J. Biol. Chem. 274, 6718-6725.

Bourguet, W., Ruff, M., Chambon, P., Gronemeyer, H., and Moras, D. (1995). Nature 375, 377-382.

Brown, K.K., Henke, B.R., Blanchard, S.G., Cobb, J.E., Mook, R., Kaldor, I., Kliewer, S.A., Lehmann, I.M., I enhard, J.M., Harrington, W.W., Novak, P.J., Faison, W., Binz, J.G., Hashim, M.A., Oliver, W.O., Brown, H.R., Parks, D.J., Plunket, K.D., Tong, W.Q., Menius, J.A., Adkison, K., Noble, S.A., and Willson, T.M. (1999). Diabetes 48, 1415-1424. 
Brown, P.J., Smith-Oliver, T.A., Charifson, P.S., Tomkinson, N.C., Fivush, A.M., Sternbach, D.D., Wade, L.E., Orband-Miller, L., Parks, D.J., Blanchard, S.G., Kliewer, S.A., Lehmann, J.M., and Willson, T.M. (1997). Chem. Biol. 4, 909-918.

Brown, P.J., Winegar, D.A., Plunket, K.D., Moore, L.B., Lewis, M.C., Wilson, J.G., Sundseth, S.S., Koble, C.S., Wu, Z., Chapman, J.M., Lehmann, J.M., Kliewer, S.A., and Willson, T.M. (1999). J. Med. Chem. 42, 3785-3788.

Brzozowski, A.M., Pike, A.C.W., Dauter, Z., Hubbard, R.E., Bonn, T., Engstrom, O., Ohman, L., Greene, G.L., Gustafsson, J.-A., and Carlquist, M. (1997). Nature 389, 753-758.

Chawla, A., Schwarz, E.J., Dimaculangan, D.D., and Lazar, M.A. (1994). Endocrinology 135, 798-800 Cobb, J.E., Blanchard, S.G., Boswell, E.G., Brown, K.K., Charifson, P.S., Cooper, J.P., Collins, J.L., Dezube, M., Henke, B.R., Hull-Ryde, E.A., Lake, D.H., Lenhard, J.M., Oliver, W., Jr., Oplinger, J., Pentti, M., Parks, D.J., Plunket, K.D., and Tong, W.Q. (1998). J. Med. Chem. 41, 5055-5069.

Collins, J.L., Blanchard, S.G., Boswell, G.E., Charifson, P.S., Cobb, J.E., Henke, B.R., Hull-Ryde, E.A., Kazmierski, W.M., Lake, D.H., Leesnitzer, L.M., Lehmann, J., Lenhard, J.M., Orband-Miller, L.A., Gray-Nunez, Y., Parks, D.J., Plunkett, K.D., and Tong, W.Q. (1998). J. Med. Chem. 41, 5037-5054.

Costet, P., Legendre, C., More, J., Edgar, A., Galtier, P., and Pineau, T. (1998). J. Biol. Chem. 273, 29577-29585.

Delerive, P., Furman, C., Teissier, E., Fruchart, J., Duriez, P., and Staels, B. (2000). FEBS Lett. 471, 34-38.

De Vos, P., Lefehvre, A.M., Miller, S.G., Guerre-Millo, M., Wong, K., Saladin, R., Hamann, L.G., Staels, B., Briggs, M.R., and Auwerx, J. (1996). J. Clin. Invest. 98, 1004-1009.

Dowell, P., Peterson, V.J., Zabriskie, T.M., and Leid, M. (1997). J. Biol. Chem. 272, 2013-2020.

Dreyer, C., Krey, G., Keller, H., Givel, F., Helftenbein, G., and Wahli, W. (1992). Cell 68, 879-887.

Fiedorek, F.T., Wilson, G.G., Frith, L., Patel, J., and Abou-Donia, M. (2000). Diabetes 49, 157.

Forman, B.M., Tontonoz, P., Chen, J., Brun, R.P., Spiegelman, B.M., and Evans, R.M. (1995). Cell 83, 803-812.

Forman, B.M., Chen, J., and Evans, R.M. (1997). Proc. Natl. Acad. Sci. U.S.A. 94, 4312-4317.

Gampe, R.T., Montana, V.G., Lambert, M.H., Miller, A.B., Bledsoe, R.K., Milburn, M.V., Kliewer, S.A., Willson, T.M., and Xu, H.E. (2000). Mol. Cell 5, 545-555.

Gottlicher, M., Widmark, E., Li, Q., and Gustafsson, J.A. (1992). Proc. Natl. Acad. Sci. U.S.A. 89, 4653-4657.

Guerre-Millo, M., Gervois, P., Raspe, E., Madsen, L., Poulain, P., Derudas, B., Herbert, J.M., Winegar, D.A., Willson, T.M., Fruchart, J.C., Berge, R.K., and Staels, B. (2000). J. Biol. Chem. 275, 16638-16642.

Harris, P.K., and Kletzien, R.F. (1994). Mol. Pharmacol. 45, 439-445.

Hawke, R.L., Chapman, J.M., Winegar, D.A., Salisbury, J.A., Welch, R.M., Brown, A., Franzmann, K.W., and Sigel, C. (1997). J. Lipid Res. 38, 1189-1203.

Ilenke, B.R., Blanchard, S.G., Brackeen, M.F., Brown, K.K., Cobb, J.E., Collins, J.L., Harrington, W.W., Jr., Hashim, M.A., Hull-Ryde, E.A., Kaldor, I., Kliewer, S.A., Lake, D.H., Leesnitzer, L.M., Lehmann, J.M., Lenhard, J.M., Orband-Miller, L.A., Miller, J.F, Mook, R.A., Jr., Noble, S.A., Oliver, W., Jr., Parks, D.J., Plunket, K.D., Szewczyk, J.R., and Willson, T.M. (1998). J. Med. Chem. 41, 5020-5036.

Hiragun, A., Sato, M., and Mitsui, H. (1988). J. Cell. Physiol. 134, 124-130.

Hofmann, C., Lorenz, K., Braithwaite, S.S., Colca, J.R., Palazuk, B.J., Hotamisligil, G.S., and Spiegelman, B. M. (1994). Endocrinology 134, 264-270.

Huang, J.T., Welch, J.S., Ricote, M., Binder, C.J., Willson, T.M., Kelly, C., Witztum, J.L., Funk, C.D., Conrad, D., and Glass, C.K. (1999). Nature 400, 378-382.

Issemann, I., and Green, S. (1990). Nature 347, 645-650. 
Jones, S.A., Moore, L.B., Shenk, J.L., Wisely, G.B., Hamilton, G.A., McKee, D.D., Tomkinson, N.C., LeCluyse, E.L., Lambert, M.H., Willson, T.M., Kliewer, S.A., and Moore, J.T. (2000). Mol. Endocrinol. 14, 27-39.

Kallen, C.B., and Lazar, M.A. (1996). Proc. Natl. Acad. Sci. U.S.A. 93, 5793-5796.

Kletzien, R.F., Foellmi, L.A., Harris, P.K.W., Wyse, B.M., and Clarke, S.D. (1992). Mol. Pharmacol. 42, 558-562.

Kliewer, S.A., Umesono, K., Noonan, D.J., Heyman, R.A., and Evans, R.M. (1992). Nature 358, 771-774.

Kliewer, S.A., Forman, B.M., Blumberg, B., Ong, E.S., Borgmeyer, U., Mangelsdorf, D.J., Umesono, K., and Evans, R.M. (1994). Proc. Natl. Acad. Sci. U.S.A. 91, 7355-7359.

Kliewer, S.A., Lenhard, J.M., Willson, T.M., Patel, I., Morris, D.C., and Lehmann, J.M. (1995). Cell 83, 813-819.

Kliewer, S.A., Sundseth, S.S., Jones, S.A., Brown, P.J., Wisely, G.B., Koble, C.S., Devchand, P., Wahli, W., Willson, T.M., Lenhard, J.M., and Lehmann, J.M. (1997). Proc. Natl. Acad. Sci. U.S.A. 94, 4318-4323.

Kliewer, S.A., Lehmann, J.M., and Willson, T.M. (1999). Science 284, 757-760.

Krey, G., Braissant, O., L'Horset, F., Kalkhoven, E., Perroud, M., Parker, M.G., and Wahli, W. (1997). Mol. Endocrinol. 11, 779-791.

Lee, S.S., Pineau, T., Drago, J., Lee, E.J., Owens, J.W., Kroetz, D.L., Fernandez-Salguero, P.M., Westphal, H., and Gonzalez, F.J. (1995). Mol. Cell. Biol. 15, 3012-3022.

Lehmann, J.M., Moore, L.B., Smith-Oliver, T.A., Wilkison, W.O., Willson, T.M., and Kliewer, S.A. (1995). J. Biol. Chem. 270, 12953-12956.

Lim, H., Gupta, R.A., Ma, W.G., Paria, B.C., Moller, D.E., Morrow, J.D., DuBois, R.N., Trzaskos, J.M., and Dey, S.K. (1999). Genes Devel. 13, 1561-1574.

Majer, M., Popov, K.M., Harris, R.A., Bogardus, C., and Prochazka, M. (1998). Mol. Gen. Metab. 65, 181-186.

Mangelsdorf, D.J., and Evans, R.M. (1995). Cell 83, 841-850.

Moore, L.B., Parks, D.J., Jones, S.A., Bledsoe, R.K., Consler, T.G., Stimmel, J.B., Goodwin, B., Liddle, C., Blanchard, S.G., Willson, T.M., Collins, J.L., and Kliewer, S.A. (2000). J. Biol. Chem. 275, 15122-15127.

Mukherjee, R., Davies, P.J.A., Crombic, D.L., Bischoff, E.D., Cesario, R.M., Jow, L., Hamann, L.G., Boehm, M.F., Mondon, C.E., Nadzan, A.M., Paterniti, J.R., Jr., and I leyman, R.A. (1997). Nature 386, 407-410.

Nagy, L., Tontonoz, P., Alvarez, J.G., Chen, H., and Evans, R.M. (1998). Cell 93, 229-240.

Nolte, R.T., Wisely, G.B., Westin, S., Cobb, J.E., Lambert, M.H., Kurokawa, R., Rosenfeld, M.G., Willson, T.M., Glass, C.K., and Milburn, M.V. (1998). Nature 395, 137-143.

Oberfield, J.L., Collins, J.L., Holmes, C.P., Goreham, D.M., Cooper, J.P., Cobb, J.E., Lenhard, J.M., Hull-Ryde, E.A., Mohr, C.P., Blanchard, S.G., Parks, D.J., Moore, L.B., Lehmann, J.M., Plunket, K., Miller, A.B., Milburn, M.V., Kliewer, S.A., and Willson, T.M. (1999). Proc. Natl. Acad. Sci. U.S.A. 96, 6102-6106.

Parks, D.J., Tomkinson, N.C., Villeneuve, M.S., Blanchard, S.G., and Willson, T.M. (1998). Bioorg. Med. Chem. Lett. 8, 3657-3658.

Peters, J.M., Hennuyer, N., Staels, B., Fruchart, J.C., Fievet, C., Gonzalez, F.J., and Auwerx, J. (1997). J. Biol. Chem. 272, 27307-27312.

Peters, J.M., Lee, S.S. T., Li, W., Ward, J.M., Gavrilova, O., Everett, C., Reitman, M.L., Hudson, L.D., and Gonzalez, F.J. (2000). Mol. Cell. Biol. 20, 5119-5128

Randle, P.J. (1998). Diabetes Metab. Rev. 14, 263-283.

Renaud, J.-P., Rochel, N., Ruff, M., Vivat, V., Chambon, P., and Moras, D. (1995). Nature 378, 681-689.

Repa, J.J., and Mangelsdorf, D.J. (1999). Curr. Opin. Biotech. 10, 557-563. 
Shiau, A.K., Barstad, D., Loria, P.M., Cheng, L., Kushner, P.J., Agard, D.A., and Greene, G.L. (1998). Cell 95, 927-937.

Shimkets, R.A., Lowe, D.G., Tai, J.T., Sehl, P., Jin, H., Yang, R., Predki, P.F., Rothberg, B.E., Murtha, M.T., Roth, M.E., Shenoy, S.G., Windemuth, A., Simpson, J.W., Simons, J.F., Daley, M.P., Gold, S.A., McKenna, M.P., Hillan, K., Went, G.T., and Rothberg, J.M. (1999). Nature Biotech. 17, 798-803.

Sohda, T., Mizuno, K., Tawada, H., Sugiyama, Y., Fujita, T., and Kawamatsu, Y. (1982). Chem. Pharm. Bull. 30, 3563-3573.

Sparks, R.L., Strauss, E.E., Zygmunt, A.I., and Phelan, T.E. (1991). J. Cell. Physiol. 146, 101-109.

Spiegelman, B.M. (1998). Diabetes 47, 507-514.

Sreenan, S., Keck, S., Fuller, T., Cockburn, B. and Burant, C.F. (1999). Am. J. Physiol. 276, E1119E1129.

Takada, I., Yu, R.T., Xu, H.E., Lambert, M.H., Montana, V.G., Kliewer, S.A., Evans, R.M., and Umesono, K. (2000). Mol. Endocrinol. 14, 733-740.

Tontonoz, P., Hu, E., Graves, R.A., Budavari, A.I., and Spiegelman, B.M. (1994a). Genes Devel. 8, 1224-1234.

Tontonoz, P., Hu, E., and Spiegelman, B.M. (1994b). Cell 79, 1147-1156.

Uppenberg, J., Svensson, C., Jaki, M., Bertilsson, G., Jendeberg, L., and Berkenstam, A. (1998). J. Biol. Chem. 273, 31108-31112.

Vamecq, J., and Draye, J.-P. (1989). Essays Biochem. 24, 115-225.

Willson, T.M., Cobb, J.E., Cowan, D.J., Wiethe, R.W., Correa, I.D., Prakash, S.R., Beck, K.D., Moore, L.B., Kliewer, S.A., and Lehmann, J.M. (1996). J. Med. Chem. 39, 665-668.

Willson, T.M., Brown, P.J., Sternbach, D.D., and Henke, B.R. (2000a). J. Med. Chem. 43, 527-550.

Willson, T.M., Cobb, J.E., Parks, D.J., and Blanchard, S.J. (2000b). Diabetes 49, 523.

Wilson, G.G., Abou-Donia, M., Frith, L., Patel, J., and Fiedorek, F.T. (2000). Diabetes 49, 525.

Xu, H.E., Lambert, M.H., Montana, V.G., Parks, D.J., Blanchard, S.G., Brown, P.J., Sternbach, D.D., Lehmann, J.M., Wisely, G.B., Willson, T.M., Kliewer, S.A., and Milburn, M.V. (1999). Mol. Cell 3, 397-403.

Yu, K., Bayona, W., Kallen, C.B., Harding, H.P., Ravera, C.P., McMahon, G., Brown, M., and Lazar, M.A. (1995). J. Biol. Chem. 270, 23975-23983. 
